\title{
Bioplastics from Fruit Waste
}

\section{May Zon Kyawt Oo ${ }^{1}$ Myo Thu ${ }^{2}$ and Zin Nyi Nyi Tun}

\author{
Professor $^{1}$, Lecturer $^{2}$ and Researcher ${ }^{3}$ \\ ${ }^{1-2-3}$ Department of Chemical Engineering \\ Mandalay Technological University \\ Mandalay \\ Myanmar
}

\begin{abstract}
The present research work with an emphasis on the synthesis of bioplastic material by using fruit waste mainly banana peels. Bioplastic can be defined as plastic made of biomass such as corn, banana peels and sugarcane. Making bioplastics from banana peels instead of traditional petroleum-based plastic is believed to be a successful solution to increase the efficiency of the plastic industry. The polymer produced using the banana peel blended with the glycerol could help in the formation of plastic having the characteristic features of pliability, other tests like solubility and swelling studies were conducted to ensure commercial properties of these bioplastic materials, characterization of the synthesized product was carried out by FTIR, the confirms the polymer is bioplastic. One of the most significant results obtained during the research is degradation tractability of the developed product. This paper deals with the method to generate bioplastic from banana peels and help to reduce pollution.
\end{abstract}

Key Words: Bioplastic, Fruit waste, Banana peels, Plastic, Biodegradation.

\section{INTRODUCTION}

Plastic causes environmental pollution because of having non-biodegradable characteristics and they are full of harmful byproducts and chemicals which are released during their break down process. Bio-based plastics mean plastics based on renewable resources. The pattern of production is shifting from the true biodegradable plastics to the bio-based plastics, and that trend is likely to persist in the future. Bioplastics are plastics derived from renewable biomass sources, such as vegetable fats and oils, corn starch, pea starch, or micro biota. Bioplastics are thus made from waste materials and not from products intended for food production. There are a variety of materials that bioplastics can be composed of, including: starch, cellulose or other biopolymers. $[1,3]$.

There is need to produced plastics from our biosphere in an "ecofriendly" fashion. However, the high production cost and the availability of low cost petrochemical derived plastics led to bioplastics being ignored for a long time. A recent global trend is to use natural, renewable, alternative resources that are beneficial in developing new materials [2,4]. This study aims to investigate the biodegradability, water absorption test, swelling and solubility of produce biodegradable plastic and to characterize the films in term of functional grop.

\section{METHOD AND EXPERIMENTAL PROCEDURE}

Fruit waste(Banana peels) are collected from the Local market at Patheingyi Township, Mandalay Region.

\subsection{Preparation of Banana skins}

Step 1: Banana peels were removed using stainless steel knife and converted into small pieces. Then peels were dip in sodium metabisulphite $\left(\mathrm{Na}_{2} \mathrm{~S}_{2} \mathrm{O}_{5}\right)(0.2 \mathrm{M})$ solution for 45 minutes.

Step 2: Banana peels were boiled in distilled water for about 30 minutes.

Step 3: The water was decanted from the beaker and the peels were now left to dry on filter paper for about 30 minutes.

Step 4: After the peels were dried, they were placed in a beaker and using a hand blender, the peels were pureed until a uniform paste was formed. 


\subsection{Production of the Plastic}

Step 1: $25 \mathrm{gm}$ of banana paste was placed in a beaker

Step 2: $3 \mathrm{ml}$ of $\mathrm{HCl}$ was added to this mixture and stirred using glass rod.

Step 3: $2 \mathrm{ml}$ of (15\% Glycerol) was added and stirred.

Step 4: $3 \mathrm{ml}$ of $\mathrm{NaOH}$ was added to this mixture and stirred, after a desired residence time.

Step 5: The mixture was spread on a ceramic tile and this was put in the oven at $120 \mathrm{o} \mathrm{C}$ and was baked till dry.

Step 6: The tile was allowed to cool and the film was scraped off the surface.

\subsection{Fourier Transform Infrared Spectroscopy (FTIR) Characterization}

A small piece was cut from the bioplastic film and placed onto the germanium plate. The spectra were taken in 256 scans between 4000 and $500 \mathrm{~cm}-1$ using the Spectrum 100 Perkin Elmer FTIR.

\subsection{Water Absorption Test}

A small piece of the sample was cut into $1 \mathrm{~cm} \times 2 \mathrm{~cm}$ size. The initial weight of the sample was recorded. The sample was then placed into a beaker containing $60 \mathrm{~mL}$ of water at room temperature for 24 hours [5].The sample was then taken out from the water and wiped off. The final weight was recorded. The amount of water uptake was calculated by using the following formula:

$$
\mathrm{WA}(\%)=\frac{\text { Final weight }(\mathrm{g}) \text {-initial weight }(\mathrm{g})}{\text { initial weight }(\mathrm{g})} \times 100
$$

\subsection{Biodegradability}

Two $400 \mathrm{ml}$ beakers and 1.1 grams of a pre-weighed piece of bioplastics were taken, the pre-weighed bioplastic material prepared was placed under the beaker containing soil at a depth of $5 \mathrm{~cm}$ from the surface. Some amount of water was sprinkled on the soil so that bacterial enzymatic activities could be enriched. These samples were kept in the beaker for about 15 days and each 3 days of interval, the specimens from the soil were taken and washed with distilled water. After that, the specimens were dried and the weight taken. And then, we observed the decrease in the weight of the bioplastic material and results were recorded accordingly, each experiment was done in triplicate in order to ensure results [5].

\subsection{Swelling tests}

Swelling study is generally conducted to check whether developed material retains the original properties when it was formed during the preparations. A pre-weighed piece of samples were prepared were taken in the test tube to check the protuberance and other morphological changes, it was carried out on the medium containing various solvents such as water, chloroform and methanol medium. Where the deliberated samples were kept in the medium for about 2 hours and the results were recorded accordingly [5].

\subsection{Solubility Test}

Two types of bioplastic were prepared and solubility studies were conducted to check persistence of these bioplastic materials. Samples of bioplastic from banana peel were soaked in sodium meta bisulfite solution and samples of bioplastic of banana peel which was obtained by a direct squeezing process were considered. All the samples were cut into small pieces and were inserted into a test tube containing different solvents [5].

\section{RESULTS AND DISCUSSION}

\subsection{Experimental Runs Conducted}

The experimental was carried out eight runs for the production of bioplastic by changing the concentration of $\mathrm{HCl}$ and $\mathrm{NaOH}$. Residence time is also important for the production of bioplastic weight. The weight of the dry film (bioplastic) obtained from eight experiments are shown in Table 1 and Table 2 
International Journal of Advances in Scientific Research and Engineering (ijasre), Vol 5 (8), August-2019

Table1. Weight of the dry film (bioplastic) results for $0.1 \mathrm{M}(\mathrm{HCl}$ and $\mathrm{NaOH})$

\begin{tabular}{|c|c|c|c|l|}
\hline $\begin{array}{c}\text { Amount of the } \\
\text { paste(m) }\end{array}$ & $\begin{array}{c}\text { Residence time } \\
(\mathbf{m i n})\end{array}$ & $\begin{array}{c}\text { Concentration of } \\
\mathbf{H C l}(\mathbf{M})\end{array}$ & $\begin{array}{c}\text { Concentration of } \\
\mathbf{N a O H}(\mathbf{M})\end{array}$ & $\begin{array}{c}\text { Weight of the } \\
\mathbf{d r y} \text { film(gm) }\end{array}$ \\
\hline 25 & 5 & 0.1 & 0.1 & 1.5575 \\
\hline 25 & 10 & 0.1 & 0.1 & 1.8420 \\
\hline 25 & 15 & 0.1 & 0.1 & 1.8498 \\
\hline 25 & 20 & 0.1 & 0.1 & 1.5115 \\
\hline
\end{tabular}

Table2. Weight of the dry film (bioplastic) results for $0.5 \mathrm{M}(\mathrm{HCl}$ and $\mathrm{NaOH})$

\begin{tabular}{|c|c|c|c|c|}
\hline $\begin{array}{c}\text { Amount of the } \\
\text { paste }(\mathrm{ml})\end{array}$ & $\begin{array}{c}\text { Residence time } \\
(\mathrm{min})\end{array}$ & $\begin{array}{c}\text { Concentration of } \\
\mathrm{HCl}(\mathrm{M})\end{array}$ & $\begin{array}{c}\text { Concentration of } \\
\mathrm{NaOH}(\mathrm{M})\end{array}$ & $\begin{array}{c}\text { Weight of the dry } \\
\text { film(gm) }\end{array}$ \\
\hline 25 & 5 & 0.5 & 0.5 & 2.4186 \\
\hline 25 & 10 & 0.5 & 0.5 & 2.0973 \\
\hline 25 & 15 & 0.5 & 0.5 & 2.0337 \\
\hline 25 & 20 & 0.5 & 0.9791 \\
\hline
\end{tabular}

\subsection{Fourier Transform Infrared Spectroscopy (FTIR) Characterization}

FTIR Analysis of the Changes in the Functional Groups of Bioplastic (BP 1) and (BP2) as described by Figure 1 and Figure 2.

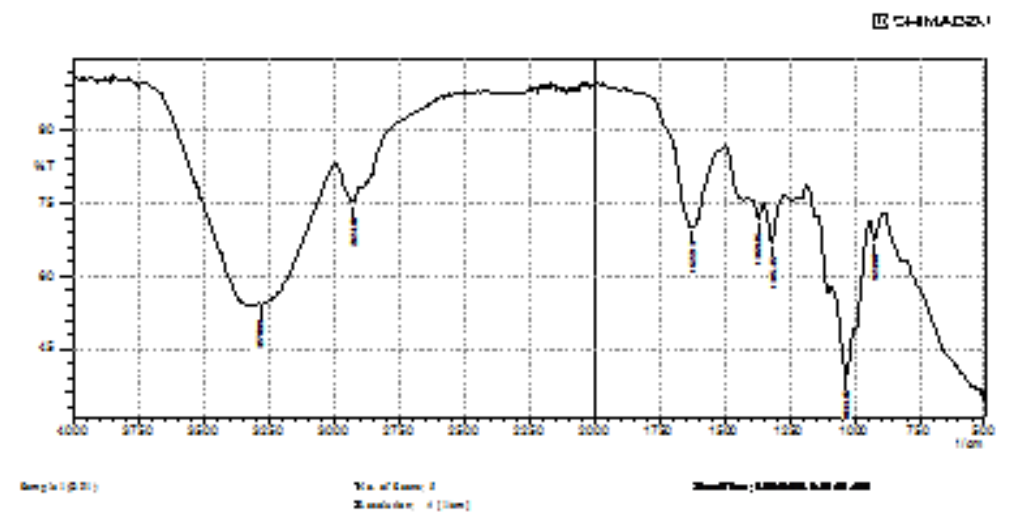

Figure1. FTIR Analysis of the Changes in the Functional Groups of Bioplastic (BP1)

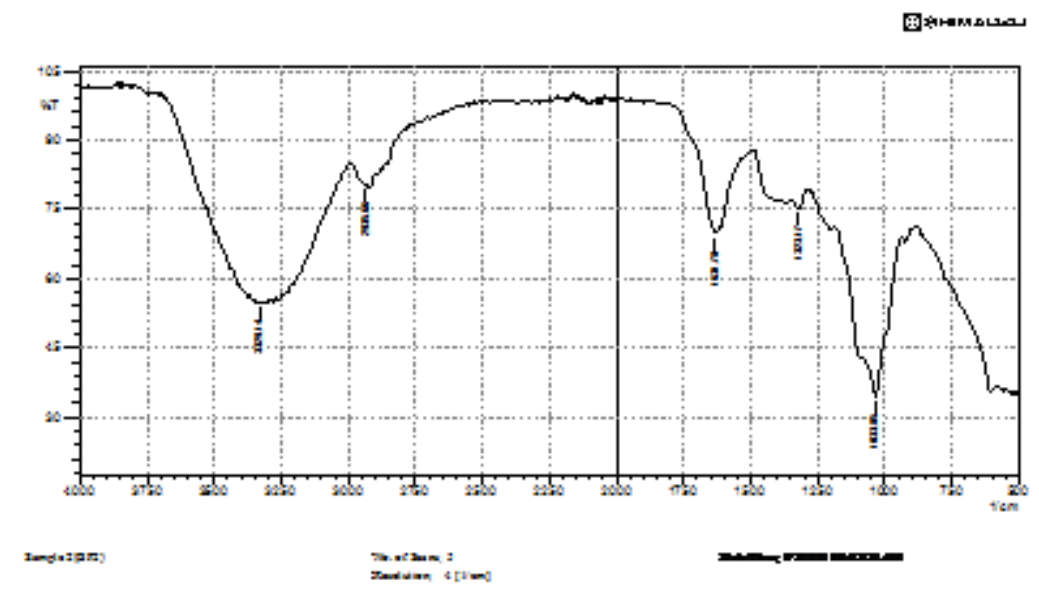

Figure 2. FTIR Analysis of the Changes in the Functional Groups of Bioplastic (BP 2) 
According to FTIR spectra, the O-H stretching peak decreases from 3324 to $3317 \mathrm{~cm}-1$ upon. The sharp peaks obtained at wavenumber 2850 to $3000 \mathrm{~cm}-1$ indicates the $\mathrm{C}-\mathrm{H}$ bond stretching of $\mathrm{CH} 2$ groups in the starch structure. The peaks discovered at wavenumber 1580 to $1700 \mathrm{~cm}-1$ in both spectra assigned to the $\mathrm{OH}$ group deflection of water. Other peaks identified in both spectra were between the range of 1400 to $1450 \mathrm{~cm}-1$ corresponding to $\mathrm{O}-\mathrm{H}$ bending, peaks at 1350 to1480 assigned to the $\mathrm{CH} 2$ bending vibrations in the biofilm, peaks at the range of $1240 \mathrm{~cm}-1$ which attributes to $\mathrm{C}-\mathrm{O}$ stretching and peaks at the range of 1720 to $1740 \mathrm{~cm}-1$ due to $\mathrm{C}=\mathrm{O}$ stretching in the film. The peaks obtained at the region below $800 \mathrm{~cm}-1$ attributed to the pyranose ring skeletal vibrations in the glucose unit of starches. The peaks at the wavenumber of $1534.45 \mathrm{~cm}-1$ and $839.57 \mathrm{~cm}-1$.

\subsection{Water Absorption Test}

Water resistance is an important characteristic in determining a suitable source for bioplastic. The water absorption of the plasticized starch BP film was carried out at room temperature for 24 hours to obtain the maximum water uptake data. Results for water absorption test obtained from eight experiments are shown in Table 3. Water absorption test obtained from eight experiments are shown in Figure 3 and Figure 4.

Table3. Results for Water Absorption Test

\begin{tabular}{|c|c|c|}
\hline Concentration of $\mathbf{H C l}$ and NaOH & Bioplastic & Results \\
\hline $0.1 \mathrm{M}$ & Sample-1 & $144.99 \%$ \\
\hline $0.1 \mathrm{M}$ & Sample-2 & $142.26 \%$ \\
\hline $0.1 \mathrm{M}$ & Sample-3 & $162.42 \%$ \\
\hline $0.1 \mathrm{M}$ & Sample-4 & $132.22 \%$ \\
\hline $0.5 \mathrm{M}$ & Sample-1 & $184.55 \%$ \\
\hline $0.5 \mathrm{M}$ & Sample-2 & $165.65 \%$ \\
\hline $0.5 \mathrm{M}$ & Sample-3 & $205.81 \%$ \\
\hline $0.5 \mathrm{M}$ & Sample-4 & $210.3 \%$ \\
\hline
\end{tabular}

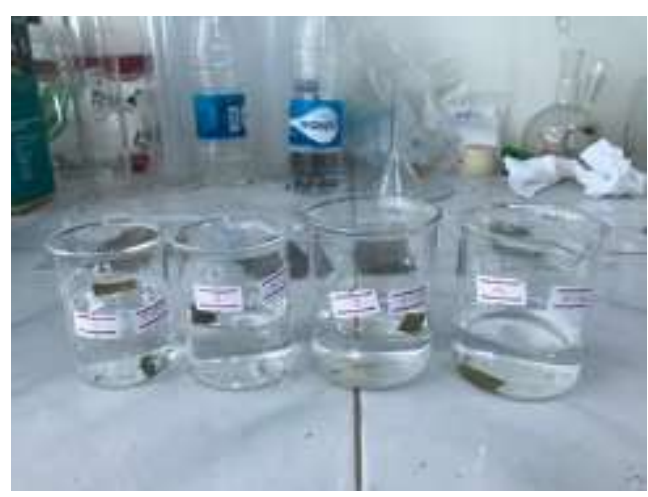

Figure 3. Water Absorption Test of Bioplastics for Concentration of (0.1M) HCl

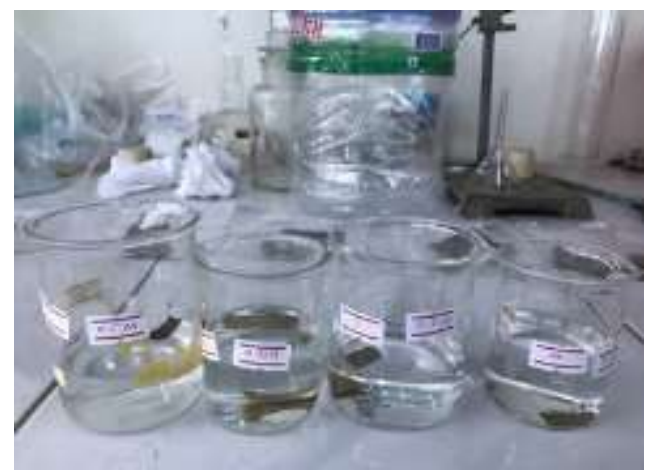

Figure4. Water Absorption Test of Bioplastics for Concentration of (0.5M) HCl 
The films were determined to have a water uptake percentage more than $50 \%$ because biopolymers are hydrophilic in nature. Besides, the water molecules interact with hydroxyl group in starch structure, the plasticization of biopolymer with glycerol is also an important factor in this study. As glycerol is a hydrophilic low molecular carbohydrates, it has the tendency to adsorb water depend on the number of hydroxyl group present and molecular weight of it structure. Glycerol has three carbons attached to their backbone with one hydroxyl group attached to each carbon which causes the molecules to bind to the highest amount of water corresponding to the weight portion. Increasing sizes of hydroxyl groups concentration centre in biocomposite matrix increases the water absorption of the film.

\subsection{Biodegradability of Bioplastic}

There are reduced in the weights of both banana peel plastic treated with sodium metabisulfite and banana peel plastic untreated preparations and these are very much desired properties for the typical bioplastic. Indicated the biodegradability of bioplastic material is shown in Table 4.The degradation studies (soil burial test) conducted is helpful in preparation of environmental friendly product and as they derived from natural polymers, they can be reused in bio compost preparation. This versatility of bioplastic plays key role in green applications.

Table4. Indicated the Biodegradability of Bioplastic Material

\begin{tabular}{|c|c|c|c|c|c|c|}
\hline Bioplastics & $\begin{array}{c}\text { Initial quantity taken } \\
\text { in grams }\end{array}$ & $\begin{array}{c}\text { Observation } \\
\text { after 3 days }\end{array}$ & 6 days & 9 days & 12 days & 15 days \\
\hline $\begin{array}{c}\text { Sample 3 } \\
(0.1 \mathrm{M})\end{array}$ & 1.1 & 0.7845 & 0.6972 & 0.4372 & 0.4345 & 0.4173 \\
\hline $\begin{array}{c}\text { Sample 2 } \\
(0.5 \mathrm{M})\end{array}$ & 1.1 & 0.6875 & 0.5433 & 0.4203 & 0.4096 & 0.3896 \\
\hline
\end{tabular}

\subsection{Swelling Tests}

There is no much change in the integrity of bioplastic material when the bioplastic material which is soaked in chloroform and methanol solvents. However, there is a slight increase in the weight of bioplastic material when it is soaked in water has made it a reliable material than other materials. The apperance of the bioplastic hasn't changed much, but there is a slight increase in the weight of the samples after 2 hours. Results for swelling test of bioplastic is shown in Table 5. Swells little higher in water as a medium and this is a desirable result because most of the additives are prepared by using organic solvents, certainly it will help in stabilize product synthesis and development.

Table 5. Results for Swelling Test

\begin{tabular}{|c|c|c|c|c|c|}
\hline $\begin{array}{c}\text { Bioplastic } \\
\text { derived from }\end{array}$ & $\begin{array}{c}\text { Solvent } \\
\text { medium }\end{array}$ & $\begin{array}{c}\text { Quantity } \\
(\mathrm{ml})\end{array}$ & $\begin{array}{c}\text { Initial weight of } \\
\text { the sample }(\mathrm{gm})\end{array}$ & $\begin{array}{c}\text { Final weight of } \\
\text { the sample }(\mathrm{gm})\end{array}$ & $\begin{array}{c}\text { Difference } \\
\text { weight }(\mathrm{gm})\end{array}$ \\
\hline $\begin{array}{c}\text { Banana peels } \\
(0.1 \mathrm{M})\end{array}$ & Water & 10 & 1 & 2.34 & 1.34 \\
\hline $\begin{array}{c}\text { Banana peels } \\
(0.1 \mathrm{M})\end{array}$ & Chloroform & 5 & 1 & 1.03 & 0.03 \\
\hline $\begin{array}{c}\text { Banana peels } \\
(0.1 \mathrm{M})\end{array}$ & Methanol & 5 & 1 & 1.17 & 0.17 \\
\hline $\begin{array}{c}\text { Banana peels } \\
(0.5 \mathrm{M})\end{array}$ & Water & 10 & 1 & & 2.08 \\
\hline
\end{tabular}


International Journal of Advances in Scientific Research and Engineering (ijasre), Vol 5 (8), August-2019

\begin{tabular}{|c|c|c|c|c|c|}
\hline $\begin{array}{c}\text { Banana peels } \\
(0.5 \mathrm{M})\end{array}$ & Chloroform & 5 & 1 & 1.08 & 0.08 \\
\hline $\begin{array}{c}\text { Banana peels } \\
(0.5 \mathrm{M})\end{array}$ & Methanol & 5 & 1 & 1.1 & 0.1 \\
\hline
\end{tabular}

\subsection{Solubility Tests}

None of the samples were completely soluble in the different medium used and these are certainly desired results for preparation of bioplastics in comparison to the traditionally used and shows the bioplastic materials prepared using the banana peel is stable. Results for solubility study of bioplastic is shown in Table 6. Solubility are the main properties to check whether the synthesized bioplastic material is sustainable or not. If the bioplastic material possesses the property of less or zero engorgement property that can be considered as excellent material with stability as characteristic features.

Table 6. Results for Solubility Study

\begin{tabular}{|l|l|l|c|c|}
\hline Solvents used & Samples & Insoluble & Partially soluble & $\begin{array}{c}\text { Completely } \\
\text { soluble }\end{array}$ \\
\hline Water & $\begin{array}{l}\text { Bioplastics } \\
(0.1 \mathrm{M})\end{array}$ & Yes & - & - \\
\hline Sulfuric acid & $\begin{array}{l}\text { Bioplastics } \\
(0.1 \mathrm{M})\end{array}$ & Yes & - & - \\
\hline Ethyl alcohol & $\begin{array}{l}\text { Bioplastics } \\
(0.1 \mathrm{M})\end{array}$ & Yes & - & - \\
\hline Water & $\begin{array}{l}\text { Bioplastics } \\
(0.5 \mathrm{M})\end{array}$ & Yes & & - \\
\hline Sulfuric acid & $\begin{array}{l}\text { Bioplastics } \\
(0.5 \mathrm{M})\end{array}$ & Yes & & - \\
\hline Ethyl alcohol & $\begin{array}{l}\text { Bioplastics } \\
(0.5 \mathrm{M})\end{array}$ & Yes & & - \\
\hline
\end{tabular}

\section{CONCLUSION}

Bioplastic film can sustain the weight near about $2 \mathrm{~g}$. The bioplastic prepared from banana peels that can be used as packaging material or as a carrying bag. Glycerol is added as plasticizer that increases its flexibility. To prevent growth of bacteria and fungi sodium metabisulphite is used. The degradation of bioplastic starts after 3 to 15 days from the date of manufacture. The atmospheric condition also effects on degradation period of bioplastic. Banana peel bioplastic is a biodegradable and an environment friendly alternative compared to conventional plastics. Research into bioplastic development should continue so that bioplastics with more diverse applications can be created from fruit waste. The main advantage of bioplastics over conventional plastic is that they degrade into environment without creating any pollution. Bioplastics is one the best replacement over conventional plastic. By using banana peels as a raw-material we can produce good quality bioplastics which has good life.

\section{ACKNOWLEDGMENT}

The author is grateful to the Mandalay Technological University, Chemical Engineering Department for providing Lab Equipment. We are also thankful towards all the available resources at University that have helped us in our research most importantly being the laboratories and the university library. 


\section{REFERENCES}

1. Y.J Chen, “Bioplastic and their role in achieving global sustainability,”J. Chem.Pharm.Res, vol. 6, pp.226-231, 2014.

2. M.R.Gaonkar, "Production of Bioplastic from Banana Peels"IIER. Hong Kong,2017

3. Noor Fatimah Kader Sultan and Wan Lutfi Wan Johari, "The Development of Banana Peel/Corn starch Bioplastic Film: A Preliminary Study" BSTR. Malaysia, vol. 5, pp.17-17, 2017

4. Aslihan Arikan. "Bioplastic.” Packaging Bulletin.2009

5. Jayachandra Yaradoddi, "Biodegradable Plastic Production From Fruit Waste Material And Its Sustainable Use For Green Application.”, IJPRPM. India, 2016 